\title{
Training Patient for Definite Treatment with the Pre-Definitive Treatment Prosthesis or the Rehabilitation Device - A Case Report
}

\author{
Harisha Dewan \\ Department of Prosthetic Dental Sciences, College of Dentistry, Jazan University, Jazan, KSA
}

Correspondence should be addressed to Harisha Dewan, harisha.dewan@yahoo.com

Received: August 23, 2020; Accepted: September 09, 2020, Published: September 16, 2020

\begin{abstract}
Severe morphological changes and the reduction of the residual ridge in old denture wearers can pose major challenges like providing optimum retention, stability, support and restoring the lost vertical dimensions in the new dentures. In addition, wearing such dentures with decreased or poor function can impair mastication and lead to harmful effects on the nutritional status of the patients. A rehabilitation device, often called a transitional denture or pre-definitive treatment prosthesis often provides a fine springboard from which to construct the second set of dentures. The present case report describes a method to restore the lost occlusal vertical dimension with a pre-definitive treatment prosthesis using the old complete dentures for a patient for him to adapt to the changes before the fabrication of the new complete dentures.
\end{abstract}

\section{KEYWORDS}

Rehabilitation device; Transitional denture; Pre-definitive treatment prosthesis; Case report

\section{INTRODUCTION}

Before a dentist starts treating an edentulous patient, the healthy state of oral mucosa is a must. The dentures constructed otherwise will be of no use to the patients. Though patients may present with some underlying conditions for their first denture, it is not uncommon to find that those seeking a new set are often in need of a pre-prosthetic treatment [1].

Most patients believe that once the complete dentures are given; there is no need for further treatment. The consequences of long term denture wearing would be wearing of acrylic occlusal surface, resorption of alveolar bone, excessive freeway space and development of memory pattern. The dependency of patients on their dentures and long term consequences can lead to changes in the occlusal vertical dimension and intercuspal position. Decrease in the vertical dimension will lead to a protrusive path of closure which can be anatomic or habitual and this consistent protruded position is difficult to record. Such patients' most common complaints are their inability to chew food, teeth that don't show as much as they used to and decreased distance between nose and chin. There are major uncertainties concerning jaw relations in these patients like, the recording of correct jaw relations in horizontal plane leading to the proper protrusion, and tolerable increase in occlusal vertical dimension which might be a problem because there is an increase in the masticatory load to the mucosa.

Citation: Harisha Dewan, Training Patient for Definite Treatment with the Pre-Definitive Treatment Prosthesis or the Rehabilitation Device - A Case Report. Case Rep Dent Sci 1(2): 40-45. 
The patient also feels that a mouthful of food cannot be taken.

A transitional denture often offers a minimal time loss and fulfilling a great need for socially active persons [2]. Even during the fabrication time of new dentures, patient has his previous denture giving him a psychological boost up. Also, it is beneficial for the treating dentist to have a clearer estimation of the tissue response of the patient during this time period and his acceptance of the increased vertical dimension of occlusion. Transitional dentures or pre-definitive treatment prosthesis or rehabilitation devices [1] are a modification of patients existing dentures or construction of prosthesis on 'copy dentures', occasionally, can be a special appliance, as the old denture may be irreversibly altered.

Achieving a correct occlusal vertical dimension (OVD) is must for constructing new complete dentures in harmony with the patient's masticatory system $[3,4]$. Though there is no exact scientific procedure for the correct determination of the occlusal vertical dimension [5-7], it is still very crucial as it decides the chewing capacity of the dentures, the aesthetics, and even phonetics [8,9].

\section{CASE REPORT}

A 52-years-old male patient reported to the Department of Prosthodontics in JSS Dental College and Hospital, Mysore with the chief complaint of worn out and loose dentures and inability to chew food (Figure 1). The patient was not aware of any significant medical history. The patient had been wearing the dentures for about 12 years. Intraoral and extra oral examinations were conducted and the main findings were: worn out complete dentures, reduced lower facial height, protrusion of the mandible, deviation towards right side upon closing, flabby left lower ridge and excessive freeway space of $8 \mathrm{~mm}$.

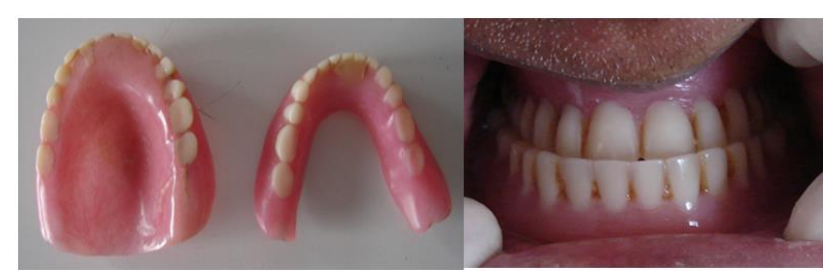

Figure 1: Patient's worn out old dentures. Deviation towards right side when patient tried to close in centric.

The original dentures were used to record the jaw relations. Two points were marked; one on the tip of the nose and other on the tip of the chin. Modelling wax (modelling wax, DPI, Mumbai, India) was added on the incisal and occlusal surfaces of the teeth so that the incisal plane, anteriorly, appeared parallel to the interpupillary line. The upper lip was also taken as a guide. The occlusal plane, posteriorly, was made parallel to the ala-tragus line. Then the lower denture with added wax was adjusted to meet evenly with the upper rim and reduced until sufficient interocclusal distance was obtained. The patient was asked to bite and the vertical dimension of occlusion (VDO) was recorded as $65 \mathrm{~mm}$ by recording the distance between the earlier marked points. The patient was made to sit upright and the physiological method was used to record the vertical dimension at rest which was about $68 \mathrm{~mm}$, leading to a freeway space of about $3 \mathrm{~mm}$. The following observations suggested establishing the correct VDO: 1. Visual observation of $3 \mathrm{~mm}$ of space between the added waxes when the mandible was in its physiological rest position. 2. Judgement of the overall aesthetic facial support. 3. Observing sounds like "s" and "ch" being enunciated accurately.

The dentures were then used to establish a preliminary centric relation record for transfer via an arbitrary mounting. Centric and eccentric relations can be recorded through the positional wax method, functional recordings, graphic recordings, and cephalometrics [10]. The patient was trained to close in centric relation by touching the tip of the tongue to the posterior part of the palate and then closing. The dentures were returned to 
the mouth for repeated trial closures and the centric relation was confirmed. No deviation was seen (Figure 2).

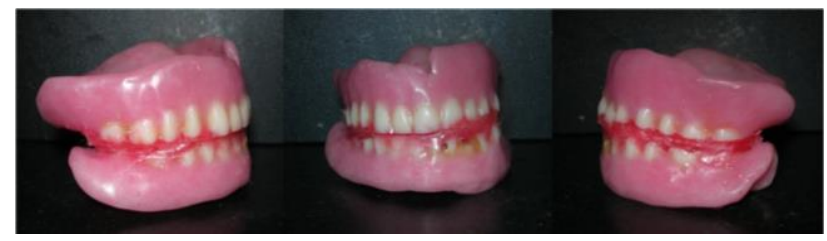

Figure 2: Patient's jaw relations-as seen extraorally.

The dentures were next placed on the master casts (obtained from blocking the undercuts inside the denture and then pouring them with elite stone by Zermack) and transferred to the mean value articulator (Figure 3).
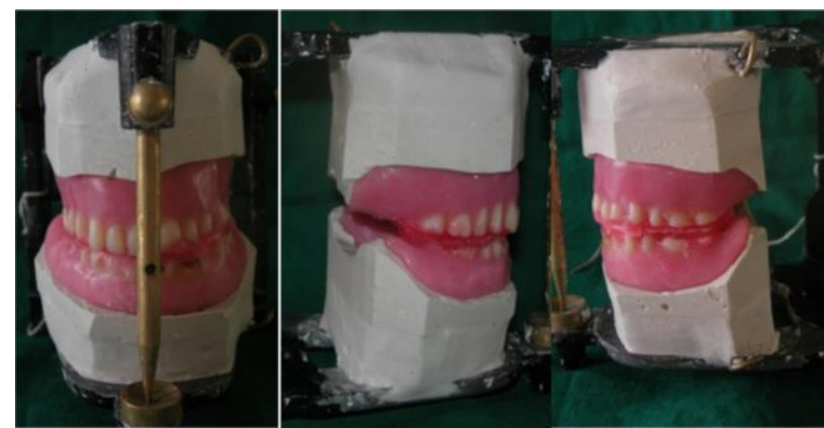

Figure 3: Jaw relation mounted- no deviation seen.

Plaster indices (made from dental plaster Gyprock) were made on the upper and lower arches (Figure 4). Wax was then removed with hot water and tooth colored acrylic resin (Novacryl, Medidental Corp) was filled onto the plaster indices one by one and placed on their respective occlusal portions (Figure 5).

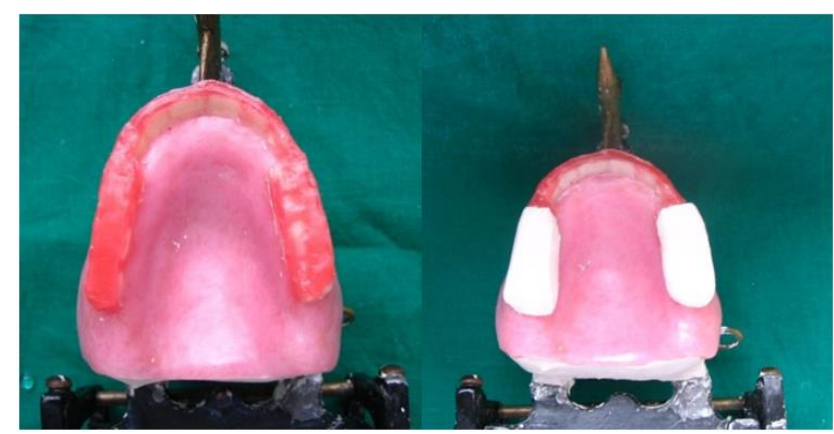

Figure 4: Plaster index made on the wax.

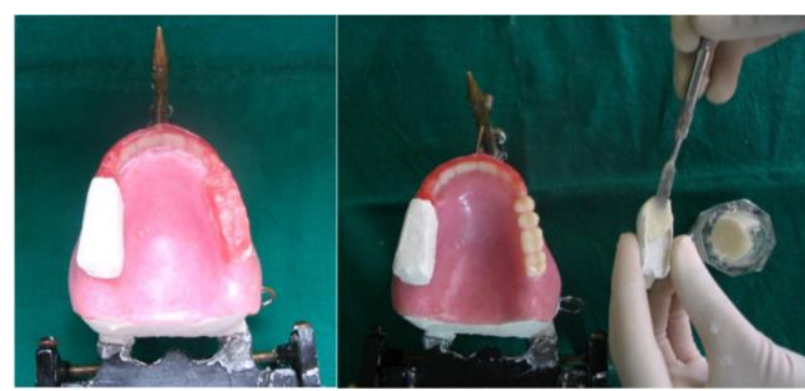

Figure 5: Wax removed with hot water and the plaster index filled with tooth coloured acrylic resin.

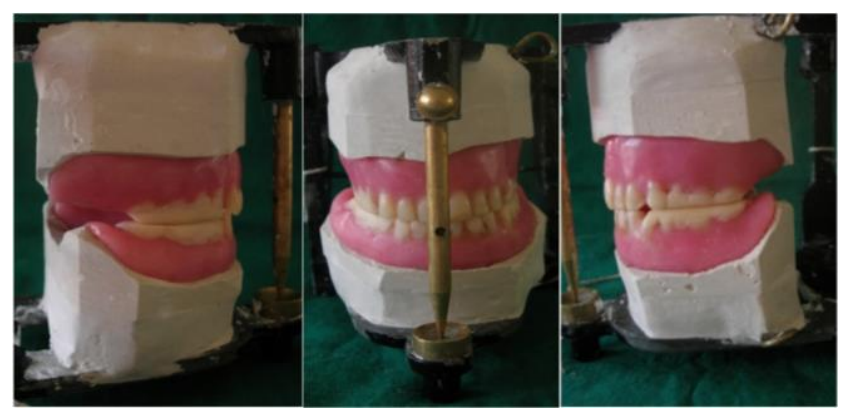

Figure 6: Tooth colored acrylic resin in the form of blocks/planes.

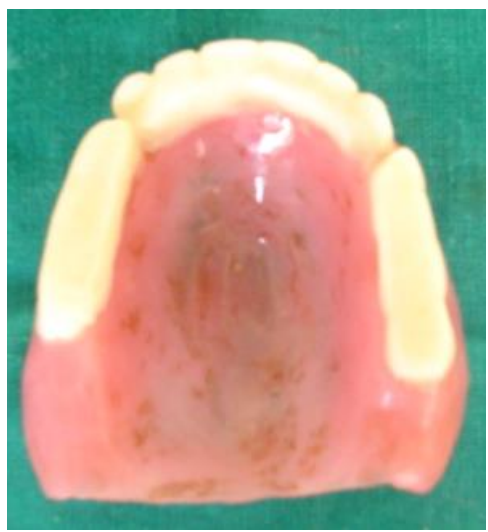

Figure 7: Upper training denture with anterior palatal inclined plane and posterior acrylic blocks/planes.

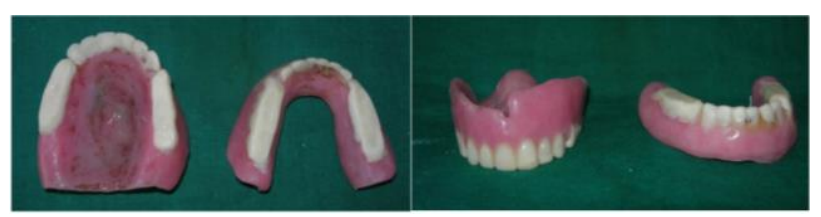

Figure 8: Upper and lower transitional dentures/rehabilitation devices with acrylic blocks in posterior region.

Tooth coloured resin was seen as flat planes in the posterior region and as the inclined plane in the anterior region (Figure 6 and Figure 7). The original dentures were now used as pre-definitive treatment prosthesis (Figure 8). 
The patient was recalled after three weeks. The patient presented with no deviation, acceptable VD which was comfortable to the patient, adequate freeway space and acceptable aesthetics. Usual procedures for fabricating a new conventional denture were then initiated. Primary impressions were made using alginate (Zermack Tropicalgin alginate) for the mandibular arch and impression compound (Kerr impression compound) for the maxillary arch. Spacer design was chosen according to the selective pressure technique [11]. Multiple holes [12] were made on the lower left special tray before the final impression (Figure 9). The final impression was made with zinc oxide impression paste (DPI zinc oxide impression paste). Jaw relations were then recorded and monoplanal teeth (Tru Smile zero degree teeth) were used as the ridges were resorbed and try in was done. Finally, the upper and lower complete dentures were processed, polished and delivered (Figure 10 and Figure 11).

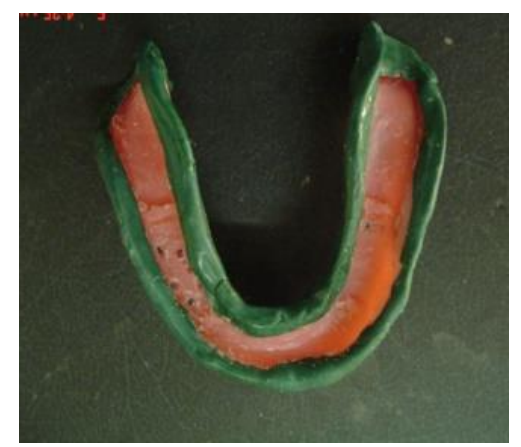

Figure 9: Lower border moulding with multiple holes in flabby ridge region.

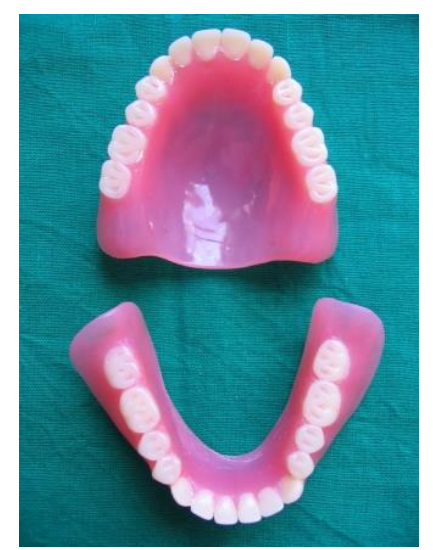

Figure 10: Upper and lower complete dentures-with monoplanal teeth.

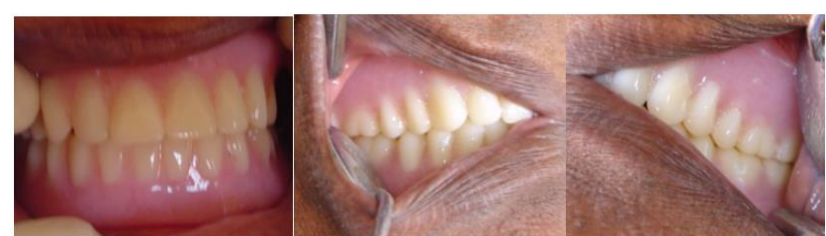

Figure 11: Dentures in occlusion.

\section{DISCUSSION}

Resorption of mandibular ridge results in a decrease in the occlusal vertical dimension and upward rotation of the mandible leading to mandibular prognathism. Because of this reason, regular appointments and timely adjustments are important to avoid extensive changes in the jaw relationships [13]. Though difficult, it is extremely important to restore the lost vertical dimension through proper treatment planning. The technique presented in this article is simple but accurate like the other electronic and computer-oriented techniques. Also, it is reversible if the patient did not adapt.

Where the freeway space is excess than normal in the existing dentures, the increase in denture height is seldom done beyond 3-4 $\mathrm{mm}$ at a time unless the tolerance potential of the patient to a greater increase in vertical dimension is first determined. This can be achieved by the use of occlusal pivots [14]. An even occlusal contact is provided allowing mandible to retruded without causing interference. If the patient can tolerate it, increase in pivot height made a few weeks later. It is a simple and non-time consuming process. Some patients do complain of inadequate space for chewing after altering their existing dentures.

Few days after the delivery of the maxillary and mandibular transitional dentures, the patient reported no problems with the prosthesis. The patient was pleased with the retention and the function. This trial phase was believed to allow neuromuscular adjustment to a change in the VDO.

In this article, the case presented describes a selective pressure impression technique using a green stick tracing 
compound for the new dentures. In order to prevent the pressure build-up and subsequent tissue compression in the flabby area, multiple relief holes were placed in the lower special tray $[15,16]$. The stability of mandibular complete denture base was enhanced through monoplane occlusion, as it reduces horizontal vectors of force at occlusal contact [17].

The use of a rehabilitation device like the one described is a reversible therapy that could improve head and cervical spine postures and re-establish the OVD [18,19], slowly and gradually allowing relaxation of the suprahyoid muscles, permitting physiological postural repositioning [20], improving the respiratory function [21] and the craniocervical posture and improving the overall aesthetics, resulting in an increase in confidence of the edentulous patients.

\section{CONCLUSION}

A rehabilitation device is a simple, effective and reversible option, allowing gradual reestablishment in the OVD and verifying the patient's adaptive ability to the suggested increase in vertical dimension before the construction of new dentures.

\section{DATA AVAILABILITY}

The cited articles are available on google scholar.

\section{CONFLICTS OF INTEREST}

The authors declare that there is no conflict of interest regarding the publication of this paper.

\section{FUNDING SOURCE}

None

\section{ACKNOWLEDGEMENT}

The author would like to extend gratitude to Dr. Anil Kumar Gujjari, JSS Dental College, Mysore, for his able guidance in completing the case.

\section{REFERENCES}

1. McCord JF, Grant AA (2000) Pre-definitive treatment: Rehabilitation prostheses. British Dental Journal 188: $419-424$.

2. Mays KA (2003) Reestablishing occlusal vertical dimension using a diagnostic treatment prosthesis in the edentulous patient: A clinical report. Journal of Prosthodontics 12(1): 30-36.

3. Yamashita S, Shimizu M, Katada H (2015) A newly proposed method to predict optimum occlusal vertical dimension. Journal of Prosthodontics 24(4): 287-290.

4. Fayz F, Eslami A (1988) Determination of occlusal vertical dimension: A literature review. The Journal of Prosthetic Dentistry 59(3): 321-323.

5. Greets GA, Stuhlinger ME, Nel DG (2004) Comparison of the accuracy of two methods used by pre-doctoral students to measure vertical dimension. The Journal of Prosthetic Dentistry 91(1): 59-66.

6. Hupfauf L (1987) Teilprothesen. Urban \& Schwarzenberg 2 Auflage 108.

7. McEntee M (2001) Complete dentures. First Bulgarian (Edn.), Sharov 32.

8. McGee GF (1947) Use of facial measurements in determining vertical dimension. The Journal of the American Dental Association 35(5): 342-350.

9. Payne SH (1964) A transitional denture. The Journal of Prosthetic Dentistry 14(2): 221-230.

10. Dewan H, Akkam TI, Chohan H, et al. (2019) Comparison of sagittal condylar guidance determined by panoramic radiographs to the one determined by conventional methods using lateral interocclusal records in the Saudi Arabian population. Journal of International Society of Preventive \& Community Dentistry 9(6): 597-604. 
http://www.tridhascholars.org | December-2020

11. Gupta A, Singhal A, Negi P (2014) Selective pressure impression technique: An overview. Journal of Evolution of Medical and Dental Sciences 3(29): 8110-8114.

12. Shikha N, Manu R (2001) Management of severely resorbed maxillary ridge with a modified light-weight hollow complete denture and monoplane teeth: A case report. International Journal of Development Research 4(10): 2001-2004.

13. Danny OM, Andressa RP, Norberto MO, et al. (2015) Reestablishment of occlusal vertical dimension in complete denture wearing in two stages. Case Reports in Dentistry 2015: 762914.

14. Yamashita S, Shimizu M, Katada H (2015) A newly proposed method to predict optimum occlusal vertical dimension. The Journal of Prosthodontics 24(4): 287-290.

15. Pardeep B, Alamjit K, Preetika B (2018) Prosthetic rehabilitation of patient with severely resorbed mandibular ridge by using neutral zone and monoplane occlusion. International Journal of Applied Dental Sciences 4(1): 259-261.

16. Bindhoo YA, Trimurthy VR, Anjana K (2012) Complete mucostatic impression: A new attempt. Journal of Prosthodontics 21(3): 209-214.

17. Sankeshwari B (2013) Impression techniques for management of flabby ridges in complete dentures - A review. Indian Dental Association Journal 46: 87-93.

18. Zanatta G, Silva WAB, Silva FA, et al. (2006) Assesment of painful symptomatology in patients with temporomandibular disorders by mean a combined experimental scale. Brazilian Journal of Oral Sciences 5(19): 12441248.

19. Casselli H, Landulpho AB, Silva WAB, et al. (2007) Electrognathographic evaluations of rehabilitated edentulous patients. Brazilian Oral Research 21(4): 355-361.

20. Urbanowicz M (1991) Alteration of vertical dimension and its effect on head and neck posture. Journal of Craniomandibular Practice 9(2): 174-179.

21. Vig PS, Showfety KJ, Phillips C (1980) Experimental manipulation of head posture. American Journal of Orthodontics 77(3): 258-268. 